vaginal examination in assessing preterm labour or the placement of a suture around the cervix in pregnancy. Both of these procedures may possibly release prostaglandins when increased uterine activity is not desirable. Our studies are being extended in these directions.

We thank Mrs H Hodgson and the staff of the John Radcliffe Hospital for their help with this study and Dr F Dray for the kind gift of antiserum. This work was supported by a grant from the Medical Research Council to ACT.

\section{References}

1 Thorburn, G D, Challis, J R G, and Currie, W B, Biology of Reproduction, 1977, 16, 18.

2 Challis, J R G, Robinson, J S, and Thorburn, G D, The Fetus and Birth, p 211. Amsterdam, Elsevier-Excerpta Medica-North Holland, 1977.

3 Turnbull, A C, et al, The Fetus and Birth, p 427. Amsterdam, ElsevierExcerpta Medica-North Holland, 1977.

' Gustavii, B, The Fetus and Birth, p 343. Amsterdam, Elsevier-Excerpta Medica-North Holland, 1977.

${ }^{5}$ MacDonald, P C, et al, Obstetrics and Gynecology, 1974, 44, 629.
${ }^{6}$ Keirse, M J N C, and Turnbull, A C, British fournal of Obstetrics and Gynaecology, 1976, 83, 146

${ }^{7}$ Mitchell, M D, et al, British fournal of Obstetrics and Gynaecology, 1975, $\mathbf{8 4}, 35$.

8 Flint, A P F, et al, fournal of Reproduction and Fertility, 1975, 43, 551.

${ }^{9}$ Mitchell, M D, Flint, A P F, and Turnbull, A C, fournal of Reproduction and Fertility, 1977, 49, 35.

10 Dray, F, Charbonnel, B, and Maclouf, J, European fournal of Clinical Investigation, 1975, 5, 311.

${ }_{11}$ Sors, H, et al, Biochemica et Biophysica Acta, 1977, 486, 553.

${ }^{12}$ Mitchell, M D, et al. Submitted for publication.

${ }^{13}$ Csapo, A I, et al, American fournal of Obstetrics and Gynecology, 1963, 85, 819

${ }^{14}$ Béguin, F, et al, Acta Physiologica Scandinavica, 1972, 86, 430

${ }^{15}$ Gréen, K, et al, American fournal of Obstetrics and Gynecology, 1974, 120, 25.

${ }^{16}$ Samuelsson, B, Les Prostaglandines, Seminaire Inserm, p 21. Paris, INSERM, 1973.

17 Swann, R O, Obstetrics and Gynecology, 1958, 11, 74.

${ }^{18}$ Mitchell, M D, Flint, A P F, and Turnbull, A C, Prostaglandins, 1975, 9,47 .

${ }^{19}$ Fisch, L, Sala, N L, and Schwarz, R L, American fournal of Obstetrics and Gynecology, 1964, 90, 108.

${ }^{20}$ Eliasson, R, Acta Physiologica Scandinavica, 1959, 158, suppl, p 1.

(Accepted 2 September 1977)

\title{
Association of serum lipids and obesity with cardiovascular mortality
}

\author{
RISTO PELKONEN， ESKO A NIKKILÄ，SEPPO KOSKINEN， KARI PENTTINEN, SEPPO SARNA
}

British Medical fournal, 1977, 2, 1185-1187

\section{Summary}

Serum lipid concentrations, relative body weight, and smoking habits were assessed in a cohort of 1648 middleaged Finnish men who were subsequently followed for seven years. Multivariate analysis showed that serum triglyceride and cholesterol concentrations and smoking were all independently associated with cardiovascular mortality. High serum triglyceride concentrations increased the risk of cardiovascular death only when they exceeded $1.7 \mathrm{mmol} / 1(150 \mathrm{mg} / 100 \mathrm{ml})$, but this occurred at all cholesterol and relative body weight levels. Obesity influenced the death rates only in men with raised serum lipid levels, while smoking was associated with increased mortality when any combination of the other factors was present. Men who had raised triglyceride concentrations combined with smoking or obesity had the highest risk of cardiovascular death.

Third Department of Medicine, University of Helsinki, Helsinki, Finland

RISTO PELKONEN, MD, consultant in endocrinology

ESKO A NIKKILÄ, MD, professor of medicine

Life Insurance Company Suomi-Salama, Helsinki, Finland

SEPPO KOSKINEN, MA, actuary

KARI PENTTINEN, MD, professor of virology

Department of Public Health Science, University of Helsinki, Helsinki, Finland

SEPPO SARNA, PHD, associate professor in biostatistics

\section{Introduction}

Several prospective studies have uniformly shown that ischaemic heart disease is closely associated with high serum cholesterol concentrations and blood pressure levels and with cigarette smoking. ${ }^{1-7}$ Raised serum triglyceride concentrations have also been connected with ischaemic heart disease, but evidence for their independent role has remained controversial. ${ }^{4} 87$ Familial hypertriglyceridaemia seems not to be associated with a high incidence of ischaemic heart disease ${ }^{8}$ : it is uncommon among patients with acute myocardial infarction and their relatives. ${ }^{\circ}$ Another factor whose status as a risk factor for ischaemic heart disease is still disputed is obesity. Some studies have shown a clear association between excessive body weight and an increased incidence of ischaemic heart disease,,$^{3510}$ but several others have not confirmed this. ${ }^{124611}$ We have investigated these problems further by conducting a seven-year prospective study in a cohort of middle-aged Finnish men. We tried to find an association between cardiovascular mortality and several supposed risk factors-serum triglyceride and cholesterol concentrations, relative body weight, and cigarette smoking-singly or in combination.

\section{Subjects and methods}

The study group was composed of men aged 50 to 53 years who had been insured with one large Finnish life insurance company (Suomi-Salama) for at least 10 years. In 1965 and 1966 all the men meeting these criteria were invited to participate in the study. Of a total of 5454 men, $39.7 \%$ responded and after those with incomplete data had been excluded a cohort of 1648 men remained.

At the start of the study each man was examined: his serum cholesterol $^{12}$ and triglyceride ${ }^{13}$ concentrations, height, and weight were measured and his smoking habits assessed. The serum lipids were analysed from a sample taken after a 12-hour overnight fast. The weight:height ratio $(\mathrm{kg} / \mathrm{m})$ was taken as a measure of the relative body weight. A smoker was defined as a person who smoked cigarettes 
regularly every day. All the pipe and cigar smokers as well as exsmokers were excluded from the smoking analysis. On these criteria there were 567 smokers and 982 non-smokers in the whole cohort.

In the seven years after the initial examination all the deaths that occurred in the cohort were registered and the causes of death were verified from official death certificates at the files of Central Bureau of Statistics. Necropsy data were available in $35 \%$ of these cases. The causes of death were divided into cardiovascular and non-cardiovascular ones. The former group included all deaths due to coronary heart disease, heart failure, cardiac arrythmia, and cerebrovascular accidents and sudden deaths. All the other causes were left to the latter group. Possible associations between the measured variables and cardiovascular mortality (CVM) were tested, firstly, by a multiple logistic discriminant analysis and, secondly, by grouping the material according to the level of each risk factor at the initial examination. The multiple logistic discriminant analysis was used to determine the joint effect of several risk factors $x_{1}, \ldots x_{p}$. The discrimination between controls and cases was based on the function $\left[1+\mathrm{e}^{-\left(\alpha+\beta^{\prime} x\right)}\right]^{-1}$, where $\mathrm{x}^{\prime}=\left(\mathrm{x}_{1}, \mathrm{x}_{2}, \ldots \mathrm{x}_{\mathrm{p}}\right)$ and $\beta^{\prime}=\left(\beta_{1}, \beta_{2}, \ldots \beta_{\mathrm{p}}\right)$. The estimation of coefficient vector and the constant term $\alpha$ was performed using the Walker-Duncan method. ${ }^{14}$ The differences between proportions were tested using the $t$ test.

The relation of serum triglyceride and cholesterol concentrations and body weight to cardiovascular deaths was further analysed by calculating the mortality separately for subgroups. These were formed by dividing the men according to whether their values for each of the variables were low, intermediate, or high. The values used to define these groupings are shown in the figures. Within each of these subgroups the cardiovascular mortality was calculated separately for men having values for another variable that were high or normal (combined low and intermediate categories, except for body weight, where the high value included both high and intermediate values).

The effect of smoking was examined by counting the death rates separately for smokers and non-smokers within the subgroups of those with normal and high values for each of the three continuous variables.

\section{Results}

CVM-The annual mortality in the cohort was 11.2 per 1000 , which is slightly less than in the basic male population of similar age. Cardiovascular disease caused 75 deaths $(58.2 \%)$ out of the total of 129 deaths. Sixty-seven men died of coronary or other heart disease and eight of cerebrovascular disease.

Serum triglyceride and CVM-In multiple logistic discriminant analysis serum triglyceride showed an independent effect in predicting CVM (see table). Total mortality was also related to triglyceride concentration but deaths not due to cardiovascular diseases showed no association. The relation between serum triglyceride and CVM was not linear, however, since the groups with low and intermediate serum triglyceride concentrations had a similar risk while those with high concentrations showed a significantly higher CVM (fig 1). This trend was similar in hypercholesterolaemic and normocholesterolaemic men as well as in obese and non-obese men. The risk of cardiovascular death in men with high concentrations of both lipids was 4.3 times that of the men with both lipids in the low range (fig 1). The risk of CVM with increasing triglyceride concentrations was more prominent in obese than in non-obese men (fig 1).

Serum cholesterol and CVM-Serum cholesterol concentration was associated with CVM even more closely than triglyceride (see table). At all cholesterol levels raised triglyceride concentrations caused a twofold to threefold increase in CVM. The influence of body weight was less clear (fig 2).

Relative body weight and CVM-Multivariate analysis showed that

Multiple logistic discriminant analysis of the relations between four different variables and mortality

\begin{tabular}{|c|c|c|c|c|}
\hline \multirow{3}{*}{ Variable } & \multicolumn{4}{|c|}{ Mortality } \\
\hline & \multicolumn{2}{|c|}{ Cardiovascular } & \multicolumn{2}{|c|}{ Total } \\
\hline & $\begin{array}{c}\text { Standard } \\
\text { coefficient }\end{array}$ & $t$ & $\begin{array}{l}\text { Standard } \\
\text { coefficient }\end{array}$ & $t$ \\
\hline $\begin{array}{l}\text { Triglyceride } \\
\text { Cholesterol } \\
\text { Relative weight } \\
\text { Smoking }\end{array}$ & $\begin{array}{l}0 \cdot 182 \\
0 \cdot 334 \\
0 \cdot 217 \\
0 \cdot 395\end{array}$ & $\begin{array}{l}1.95 \\
2.88 \\
1.78 \\
3 \cdot 26\end{array}$ & $\begin{array}{l}0 \cdot 155 \\
0 \cdot 186 \\
0.082 \\
0.500\end{array}$ & $\begin{array}{l}1.90 \\
1.97 \\
0.85 \\
5 \cdot 20\end{array}$ \\
\hline
\end{tabular}

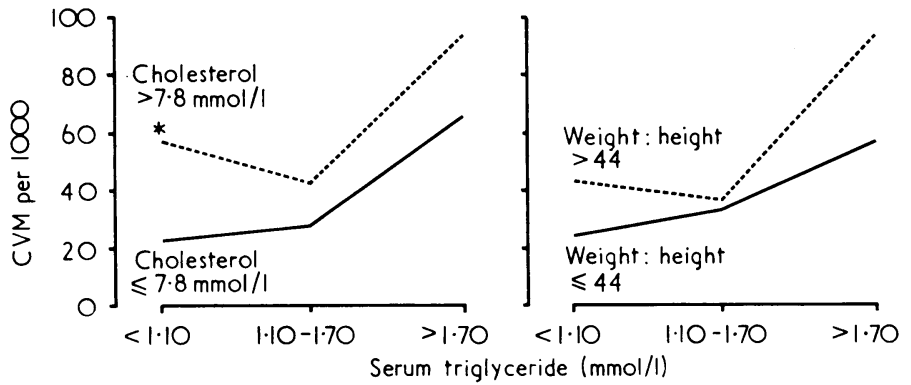

FIG 1-Cardiovascular mortality in relation to serum triglyceride concentrations.

$* \mathrm{P}<0.05$.

Conversion: SI to traditional units-Triglyceride: $1 \mathrm{mmol} 1 \approx 88.5 \mathrm{mg} / 100$ ml. Cholesterol: $1 \mathrm{mmol} / 1 \approx 38.6 \mathrm{mg} / 100 \mathrm{ml}$

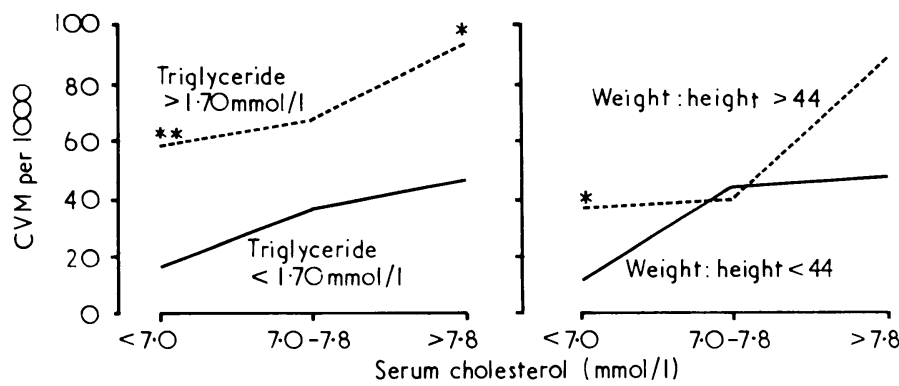

FIG 2-Cardiovascular mortality in relation to serum cholesterol concentrations.

$* \mathrm{P}<0.05 . \quad * * \mathrm{P}<0.01$

relative body weight also appeared as risk factor with an independent but weak effect (see table). Nevertheless, the effect of body weight on CVM was almost solely confined to men with raised serum lipid concentrations (fig 3). In fact body weight did not influence the CVM at all in men with normal triglyceride concentrations. The relative risk of cardiovascular death in obese hypertriglyceridaemic men was $4 \cdot 1$ times that in lean normoglyceridaemic men.

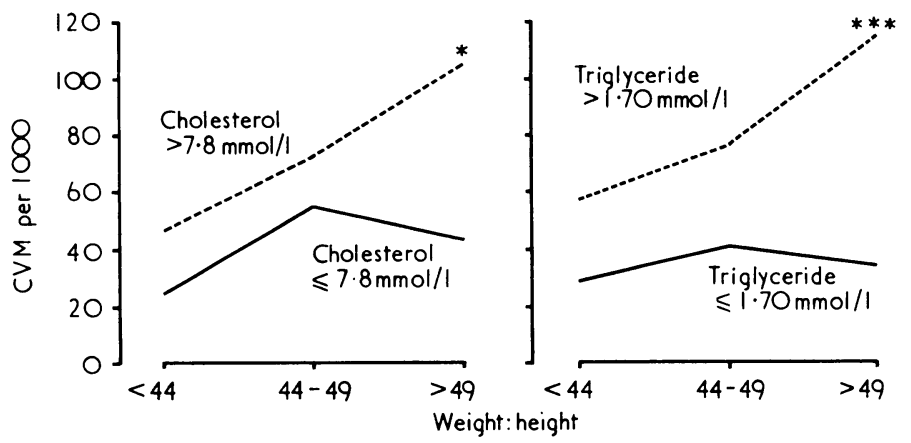

FIG 3-Cardiovascular mortality in relation to weight :height ratio. $* \mathrm{P}<0.05$. ***P<0.001.

Smoking and CVM-In multiple logistic discriminant analysis smoking appeared as a strong predictor of both CVM and noncardiovascular deaths (see table). Smoking increased the CVM at all combinations of the other variables (fig 4). Men with raised serum triglyceride concentrations who smoked had a cardiovascular death rate $5 \cdot 7$ times that of the men who had normal triglyceride concentrations and did not smoke.

Combinations of two risk variables-Among the subgroups formed of men who had high values of two variables the hypertriglyceridaemic smokers had the highest CVM (126 per 1000). Other combinations and their CVMs were: obesity and raised triglyceride concentrations (114 per 1000), obesity and raised cholesterol concentrations (104 per 1000), and combined (type IIb) hyperlipidaemia (93 per 1000). 


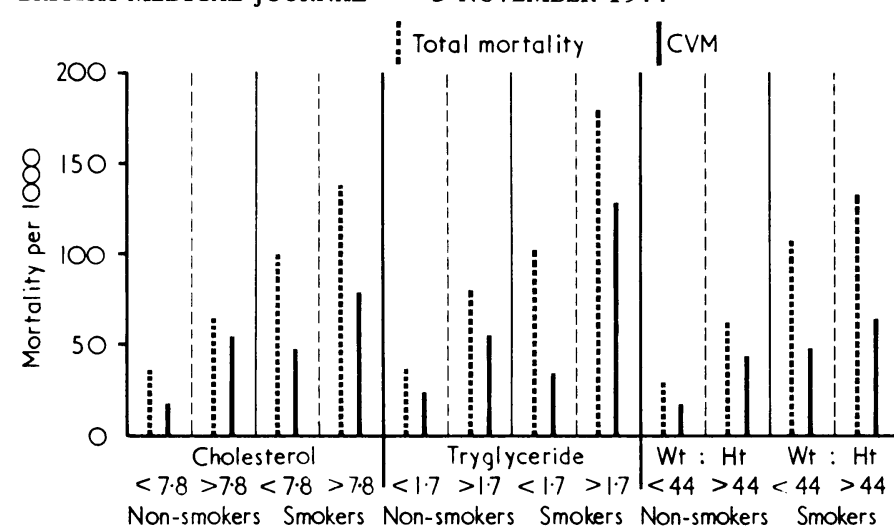

FIG 4-Total mortality and cardiovascular mortality in relation to cigarette smoking and other variables.

\section{Discussion}

Our data indicate that hypertriglyceridaemia definitely increases the probability of dying of cardiovascular causes in middle-aged men and that this effect is independent of serum cholesterol concentration, relative body weight, and smoking habits. This finding differs from the results of other prospective longitudinal studies that also used a multiple logistic risk analysis of data. ${ }^{3+} ;$ These studies showed that serum triglyceride $^{4}$ or $S_{f} 20-400$ (pre- $\beta$ ) lipoprotein ${ }^{3}$ concentration is related to coronary heart disease only through its association with serum cholesterol and has no predictive power over the latter variable. We cannot adequately explain this divergence of results. It should be noticed, however, that in the Framingham cohort a raised concentration of the triglyceride-rich $S_{f} 20-400$ lipoprotein was associated with a clearly increased risk of developing coronary heart disease ${ }^{3}$ in spite of the fact that this fraction accounts for only 10 to $20^{\circ}{ }_{0}$ of total serum cholesterol. The only prospective study that has so far shown an association between the serum triglyceride concentration and the incidence of ischaemic heart disease did not apply the multiple logistic model. ${ }^{6}$

Our results suggest that the relation between serum triglyceride concentration and CVM is not linear. Thus, the risk of CVM did not increase until values exceeded $1.7 \mathrm{mmol} / \mathrm{l}$ $(150 \mathrm{mg} / 100 \mathrm{ml})$, a concentration often considered to be the upper limit of normal. In this respect triglyceride deviates from many other cardiovascular risk variables such as serum cholesterol, blood pressure, and cigarette consumption, which are linearly correlated with disease events throughout the whole range without any critical level discriminating between safe and susceptible. Indeed, a pattern of association between triglyceride and ischaemic heart disease similar to that found here is evident also from the data of the Stockholm study, ${ }^{6}$ where a clearly increased risk was present only in the highest triglyceride quintile even though the authors suggested that there was a continuous linear regression. The basis for this difference in the risk profile of triglyceride and cholesterol is not known, but it might relate in some way to the differences in the metabolism of very-low-density and low-density lipoproteins.

The risk of CVM associated with raised serum triglyceride concentrations was considerably enhanced when some other abnormality was added. Highest incidence figures were found among the men who had a combination of hypertriglyceridaemia and obesity or smoking. In fact, obesity appeared to increase the risk of CVM sharply only in those men who had a simultaneous increase in concentrations of either of the serum lipids. This finding might account for the failure of many previous studies to show an association between obesity and cardiovascular disease. ${ }^{6}$ ?

We thank Professor Harri Nevanlinna, who allowed us to use the laboratory facilities of the Finnish Red Cross Blood Transfusion Service for the lipid analyses. This work was supported by grants from the Sigrid Juselius Foundation and from the Finnish State Medical Research Council.

Requests for reprints should be addressed to Dr R Pelkonen, Third Department of Medicine, University of Helsinki, 00290 Helsinki 29, Finland.

\section{References}

1 Morris, J N, et al, Lancet, 1966, 11, 553.

2 Keys, A, et al, Circulation, 1972, 45, 815.

${ }^{3}$ Kannel, W B, American fournal of Cardiology, 1976, 37, 269.

4 Rosenman, R H, et al, American fournal of Cardiology, 1976, 37, 903.

${ }^{5}$ Medalie, J H, et al, fournal of Chronic Diseases, 1973, 26, 329.

- Carlson, L A, and Böttiger, L E, Lancet, 1972, 1, 865.

7 Wilhelmsen, L, et al, Circulation, 1973, 48, 950.

${ }^{8}$ Brunzell, J D, et al, Metabolism, 1976, 25, 313.

${ }^{9}$ Nikkilä, E A, and Aro, A, Lancet, 1973, 1, 954.

10 Gordon, T, and Kannel, W B, Clinics in Endocrinology and Metabolism, 1976, 5, 367.

${ }^{11}$ Dyer, A R, et al, fournal of Chronic Diseases, 1975, 28, 109.

12 Abell, L, et al, fournal of Biological Chemistry, 1952, 195, 357.

${ }^{13}$ van Handel, E, and Zilversmit, D B, Fournal of Laboratory and Clinical Medicine, 1957, 50, 152.

14 Walker, S H, and Duncan, D S, Biometrika, 1967, 54, 167.

(Accepted 2 September 1977)

\section{SIDE EFFECTS OF DRUGS}

\section{Anaphylaxis after dichloralphenazone treatment}

There have been no reports of anaphylaxis after the ingestion of dichloralphenazone. A case is described of a patient who suffered this on two separate occasions.

\section{Case report}

A 66-year-old English pensioner, weighing $65 \mathrm{~kg}$, was admitted for investigation of a minor haematemesis. His only history at that time was one of recurrent dysuria over the preceding 14 years, due to benign prostatic hyperplasia. He gave no personal or family history of allergy. On examination the only abnormality was a benign enlarged prostate.

On the night of admission he was given one dichloralphenazone (Welldorm) tablet. This, together with $10 \mathrm{mg}$ oral metoclopramide, which he had taken five hours earlier, was the only medication he received.
Adverse effect-Within 15 minutes of taking the tablet he complained of a generalised itch, and a diffuse erythematous rash with periorbital oedema was noted. He then complained of chest pain and collapsed unconscious with no measurable blood pressure. An electrocardiogram (ECG) showed atrial fibrillation. He was treated with intravenous hydrocortisone, intramuscular promethazine, and oxygen by facemask, and he regained consciousness within three hours. By the next morning he was well, and an ECG was normal.

On obtaining his past medical notes we discovered that an identical reaction had been described in 1963 again after the administration of dichloral phenazone, but in view of there being no reports of this reaction it was thought to be vasovagal syncope.

\section{Comment}

Dichloralphenazone is a loose complex that releases chloral hydrate in the gastric juice. Phenazone (antipyrine) is a pyrazolone derivative which has not been associated with the same severe reactions as the other pyrazolone derivatives, in particular amidopyrine, which in 